\title{
Kahramanmaraş İli Göksun İlçesi’nde Arazi Kullanımında Meydana Gelen Zamansal Değişimin Uzaktan Algılama Teknikleri ve Coğrafi Bilgi Sistemi İle Belirlenmesi
}

\author{
Mahmut REİs ${ }^{1}$, Hurem DUTAL ${ }^{1}$, Bülent ABIZ ${ }^{1}$, Nurşen BOLAT ${ }^{1}$ \\ ${ }^{1}$ KSÜ Orman Fakültesi, Orman Mühendisliği Bölümü, Avşar Kampüsü, Kahramanmaraş
}

\begin{abstract}
ÖZET: Sürdürülebilir bir çevre için arazi kullanımında meydana gelen değişimlerin belirlenmesi ve izlenmesi gerekmektedir. Bu çalışmada, Kahramanmaraş ilinin Göksun ilçesinde 1984 ve 2011 yılları arasında arazi kullanımında meydana gelen değişim uzaktan algılama (UA) teknikleri ve coğrafi bilgi sistemleri(CBS) ile belirlenmiştir. Araştırmada, 1984 yılı Ağustos ayı ve 2011 yılı Eylül ayına ait Landsat 5 Thematic Mapper (path/row: 174/34) uydu görüntülerinden faydalanılmıştır. Her iki uydu görüntüsü ERDAS Imagine programıyla kontrollü sınıflandırma ile sınıflandırılmış, kent, tarım, orman, çayır/mera ve diğerleri (çıplak alanlar, kayalıklar, sulak alanlar, tabii ve suni göller) olmak üzere 5 sınıftan oluşan arazi kullanım katmanları üretilmiştir. Kontrollü sınıflandırma işleminin ardından her iki görüntü için doğruluk analizi yapılmıştır. Yapılan analizlerde 1984 yılı için genel doğruluk oranı \%86,80, kappa değeri 0,82, 2011 y1lı için genel doğruluk oranı \%84,40 kappa değeri 0,79 olarak bulunmuştur. Yapılan analizler sonucunda; 1984 ve 2011 yılları arasında geçen 27 yılda meydana gelen arazi kullanım değişimi haritasına göre yerleşim alanlarında \% 21,53 (10461,2 ha) ve orman alanlarında \% 28,47 (13836 ha) oranında bir artış meydana gelirken, tarım alanlarında \% 4,98 (2422,44 ha), çayır/mera alanlarında \% 16,78 $(8156,16$ ha) ve diğer alanlarda \% 28,23 (13718,61 ha) oranında bir azalma meydana gelmiştir.
\end{abstract}

Anahtar kelimeler: Uzaktan Algılama, Arazi Kullanımı, Değişim Analizi, CBS

\section{Determination Temporal Land Use Changes in Goksun District of Kahramanmaras City Using Remote Sensing Techniques and Geographic Information Systems}

\begin{abstract}
The changes in land use must be determined and monitored for a sustainable environment. In this study, the changes occurring land use in Goksun district of Kahramanmaras city were investigated by using remote sensing (RS) techniques and geographic information systems (GIS) in between 1984 and 2011. August 1984 and September 2011 satellite images belonging to Landsat 5 Thematic Mapper (path / row: 174/34) were used to determine land use changes. Both satellite images were classified with supervised classification method using Erdas Imagine programme and 5 land use classes; urban, agricultural, forest, prairie / pasture, and others (bare areas, cliffs, wetlands, natural and artificial lakes) were determined. After supervised classification process, accuracy assessment was made for both images. It was found that the overall accuracy rate was $86,80 \%$ and, the kappa value was 0,82 for 1984, while these values for 2011 were $84,40 \%$ and 0,79 respectively. According to land use change map, it was determined that increases in urban and forest areas were 21,53\% (10461,2 ha) and 28,47\% (13836 ha) respectively, however decrease in agriculture, prairie / pasture and others areas were 4,98\% (2422.44 ha), 16,78\% (8156,16 ha) and 28,23\% (13718,61 ha) respectively in between 1984 and 2011.
\end{abstract}

Keywords: Remote Sensing, Land Use, Change Detection, GIS

\section{GíRİş}

Arazi, tabii yerlerde iklimin, hidrografyanın ve bütün canlıların etkisi altında bulunan jeolojikjeomorfolojik-pedojonik oluşumları kapsayan yeryüzü parçasıdır (1). Arazi kullanımı, belirli arazi parçası ile ilgili antropojenik aktiviteleri ve ekonomik işlevini belirtmektedir (2). Arazi kullanımı, dar anlamda araziden, özellikle topraktan tarım ve ormancılık amacıyla faydalanmayı ifade ederken geniş anlamda, iskan yapmak için faydalanma, ticaret, sanat, endüstri

"Sorumlu Yazar: Nurşen BOLAT, nsen@ksu.edu.tr ve dinlenme vakitlerini değerlendirme gibi araziden her türlü faydalanmayı ifade etmektedir (3).

Türkiye'de tarımsal üretim amacıyla faydalanılabilecek olan I., II., III. ve IV. sinıflarda yer alan arazi, Türkiye'nin toplam arazi varlı̆̆ının \%34,5' ine karşılık gelmektedir. Başka bir ifadeyle, Türkiye'de arazilerin sadece üçte biri tarım yapmaya elverişlidir. Çayır, mera ve orman olarak faydalanılması gereken V., VI. ve VII. sınıftaki arazi miktarı toplam arazi varlığının \%60,9'unu oluşturmakta iken, diğer kullanım amaçları için elverişli olan VIII. sınıf araziler toplam arazi varlığının \%4,6'sını oluşturmaktadır. Verilen değerler, 
Türkiye'de arazi miktarının "optimal faydalanma şekillerini ve miktarlarını" belirtmektedir (4).

Arazi kullanımındaki değişim, doğal ve yahut antropojenik etkilerle meydana gelmektedir. Kirsal alanların yerleşim alanlarına olan dönüşümü büyük bir hızla devam etmekte olup, bu değişim dünyada hızla kentleşmeyi artırırken aynı zamanda ekosistemlerin doğal işlevlerini etkilemektedir. 1900 yılında dünya nüfusu yaklaşık olarak 1.6 milyar iken, dünyada insan popülasyonunun yalnızca \% 13'ü kentlerde yaşamıştır (5). Halbuki, 2005 yılında dünyada insan popülasyonunun $\% 49,2$ 'si kentlerde yaşarken 2030 yılında bu değerin \% 60'a varması beklenmektedir (6).

Türkiye'de hızlı nüfus artışı nedeniyle arazi kullanımlarında çok küçük zaman dilimlerinde değişimler meydana gelmekte, orman alanları ve su havzaları ciddi bir iskan tehdidine maruz kalmaktadır (7). Türkiye'de 1950'li y1llardan günümüze kadar hem sosyal hem de ekonomik koşullardan dolayı kırsal alanlardan kentsel alanlara doğru bir göç hareketi başlamış olup, nüfusun \% 75'i kentlerde yaşamaktadır (8 ve 9). Nüfusun yer değiştirmesi ile birlikte arazi kullanımında değişimler meydana gelmektedir. Örneğin, [10] (2010) Villivakkam'da yaptığı bir çalışmada 1990 ve 2005 yılları arasında kent alanlarında $\% 15,83$ 'lük bir artış tespit etmiştir. Benzer şekilde, [11] (2006) yaptıkları çalışmada, 2000 ve 1989 yıllarına ait sırayla Landsat ETM ve TM görüntüleri, 1950 ve 1985 yıllarına ait uydu görüntüleri ve hava fotoğraflarını kullanarak yaptıkları bir çalışmada, Kahramanmaraş ili yerleşim alanlarında yaklaşık 11katlık bir artış tespit etmiştir.

Arazi kullanımından meydan gelen değişimlerden dolayı, doğada büyük bir baskı oluşmaktadır. Bu durum, kıt olan doğal kaynakların bilinçli kullanımını sağlamak amacıyla dünyamız ile ilgili hızlı ve güvenilir bilgiye olan gereksinimini artırmaktadır. $\mathrm{Bu}$ ihtiyaçlar doğrultusunda tabii kaynak ve değerlerin kalite ve kantitelerine ait detaylı bilgilere ulaşmak amacıyla UA ve CBS geliştirilmiş hızlı, doğru, güvenilir ve etkili çalışmalar ile veri tabanı oluşturulma imkanı sunmaktadır (12).

Bu araştırmada, CBS ve UA teknikleri aracılığıyla Landsat $5 \mathrm{TM}+$ uydu görüntülerinden faydalanılarak Kahramanmaraş ilinin Göksun ilçesinde 1984 ve 2011 yılları arasında arazi kullanımında meydana gelen zamansal ve mekânsal değişim tespit edilmiştir.

\section{MATERYAL VE METOD}

\subsection{Araştırma Alanının Tanıtımı}

Araştırma alanını oluşturan Göksun ilçesi, Kahramanmaraş il merkezine $90 \mathrm{~km}$ uzaklıkta bulunup, Türkiye' nin Doğu Akdeniz bölgesinde yer almaktadır.
Çalışma alanı 180292,6 ha'lık bir alanı kaplamakta ve ortalama $1343 \mathrm{~m}$ bir yükseltiye sahiptir. İlçenin Kuzeyinde Kayseri'nin Sarız İlçesi, Kuzeydoğuda Afşin, doğusunda Elbistan ve Ekinözü, güneyinde Andırın ve Merkez İlçe, batısında Adana Saimbeyli, kuzeybatıda Adana Tufanbeyli ilçesi yer almaktadır. İlçenin en önemli akarsuları Ceyhan havzasında yer alan Terbüzek ve Kömür çaylarıdır. Terbüzek çayının kaynağı Mehmetbey Mahallesi, Kömür çayının kaynağı ise Kavşut mahallesinin dağlarıdır. Her iki çayda Ceyhan nehrine dökülmektedir.

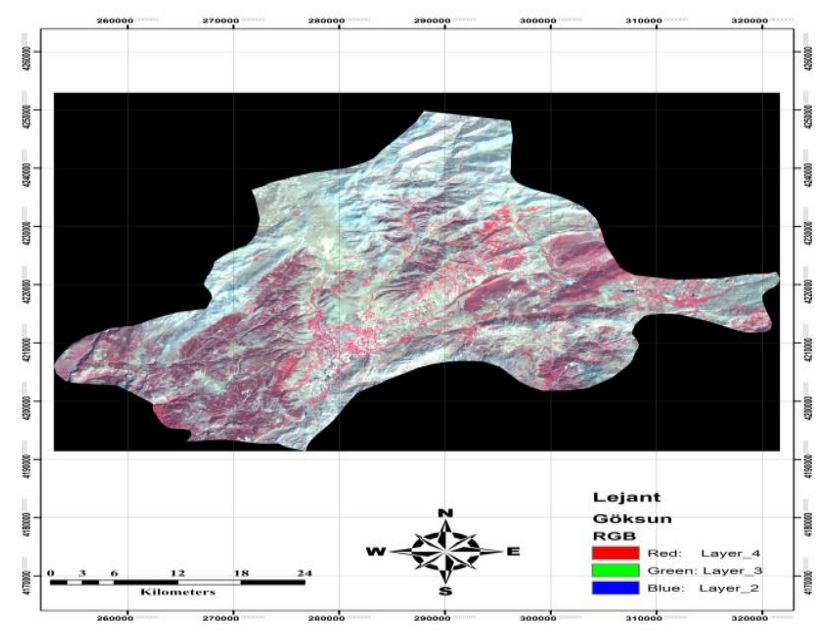

Şekil 1. Araştırma Alanı Lokasyonu

Araştırma alanında karasal iklim hüküm sürmektedir. Yazları sıcak ve kurak, kışları ise soğuk ve kar yağışı görülmektedir. En yüksek yağışı kış ve ilkbahar mevsimlerinde, en düşük yağış ise yaz mevsiminde düşmektedir. Göksun'da yıllık ortalama sıcaklık $8^{\circ} \mathrm{C}$, ortalama yağış miktarı ise $622 \mathrm{~mm}$ 'dir. Göksun oldukça engebeli arazi üzerine kurulu olup, en yüksek noktası 3027 m'lik yüksekliği ile ilçenin güneydoğusunda yer alan Berit dağıdır.

\subsection{Metod}

Bu çalışmada 5 Ağustos 1984 ve 17 Eylül 2011 tarihlerine ait Landsat Thematic Mapper (TM) uydu görüntüleri kullanılmıştır (Tablo 1). [13] (1996) ve [14] (2006)' da belirttiği üzere, konumsal ve zamansal değişimin tespiti için, mümkün olduğunca günün aynı saatlerinde ve yılın aynı vakitlerinde elde edilmiş uydu görüntülerden faydalanılmıştır.

Arazi çalışmalarının mümkün olmadığı durumlarda arazi sınıflarından imza toplamak amacıyla farklı kaynaklar (amenajman meşcere haritaları, topoğrafik haritalar vb.) kullanılmıştır (15). Kontrollü sınıflandırma yapmak amacıyla imza toplama işlemi yapılmış, alanın bitki örtüsü ile ilgili alınan ilk verilerin istatistiki altlık oluşturulmuş ve sınıflandırma işlemine 
bu altlık üzerinden devam edilmiştir (16). Uydu görüntülerinin sınıflandırılma işlemi 1- Kent, 2- Tarım, 3- Orman, 4-Çayır/mera, 5- diğerleri (Çıplak alanlar, kayalıklar, sulak alanlar, tabii ve suni göller) olacak şekilde yapılmıştır. Arazi kullanımllarına ait sınıflandırma düzeni Tablo 2'de gösterilmiştir. Yapılan bu kontrollü sınıflandırmada maksimum olasılık algoritması kullanılmıştır (13).

Tablo 1. Araştırmada Kullanılan Uydu Görüntüleri

\begin{tabular}{cccc}
\hline $\begin{array}{c}\text { Uydu } \\
\text { Görüntüsü }\end{array}$ & Tarih & $\begin{array}{c}\text { Konumsal } \\
\text { Çözünürlük }\end{array}$ & $\begin{array}{c}\text { Kullanılan } \\
\text { Bantlar }\end{array}$ \\
\hline $\begin{array}{c}\text { Landsat 5 } \\
\text { TM }\end{array}$ & 05.08 .1984 & $30 \mathrm{~m}$ & $1-2-3-4-5-$ \\
7
\end{tabular}

Tablo 2. Arazi kullanımlarının sınıflandırması

\begin{tabular}{ll}
\hline Kent & $\begin{array}{l}\text { Yerleşim alanı (kırsal ve kentsel } \\
\text { alanlar), ulaşım yolları v.b. }\end{array}$ \\
\hline Tarım & $\begin{array}{l}\text { Tarımsal alanlar, sulu ve kuru tarım } \\
\text { alanları v.b. }\end{array}$ \\
\hline Orman & $\begin{array}{l}\text { İğne ve geniş yapraklı ormanlar, } \\
\text { ağaçlandırma alanları v.b. }\end{array}$ \\
\hline Çayır/Mera & Yeşil alan, çayır, mera \\
\hline Diğerleri & $\begin{array}{l}\text { Çıplak alanlar, kayalıklar, sulak } \\
\text { alanlar, tabii ve suni göller }\end{array}$ \\
\hline
\end{tabular}

Yapılan kontrollü sınıflama işleminin doğruluk derecesinin tespiti için 1984 ve 2011 yıllarına ait uydu görüntülerinin doğruluk analizleri yapılmış ve Kappa katsayıları belirlenmiştir. Arazi kullanımının sınıflandırma doğruluğunu belirlemek amacıyla kullanılan uydu görüntüleri için 250 rastgele nokta oluşturmuştur.

Sınıflandırma analizinden sonra değişim analizi (change detection) yöntemi aracılığıyla yeni bir harita oluşturulmuştur. Böylece, bu harita üzerinden 1984 ve 2011 yılları arasındaki arazi değişim miktarı ve yeri tespit edilmiştir.

\section{BULGULAR VE TARTIŞMA}

1984 ve 2011 yıllarına ait elde edilen arazi kullanım sınıfları haritaları Şekil 2 ve 4'de gösterilmiştir.

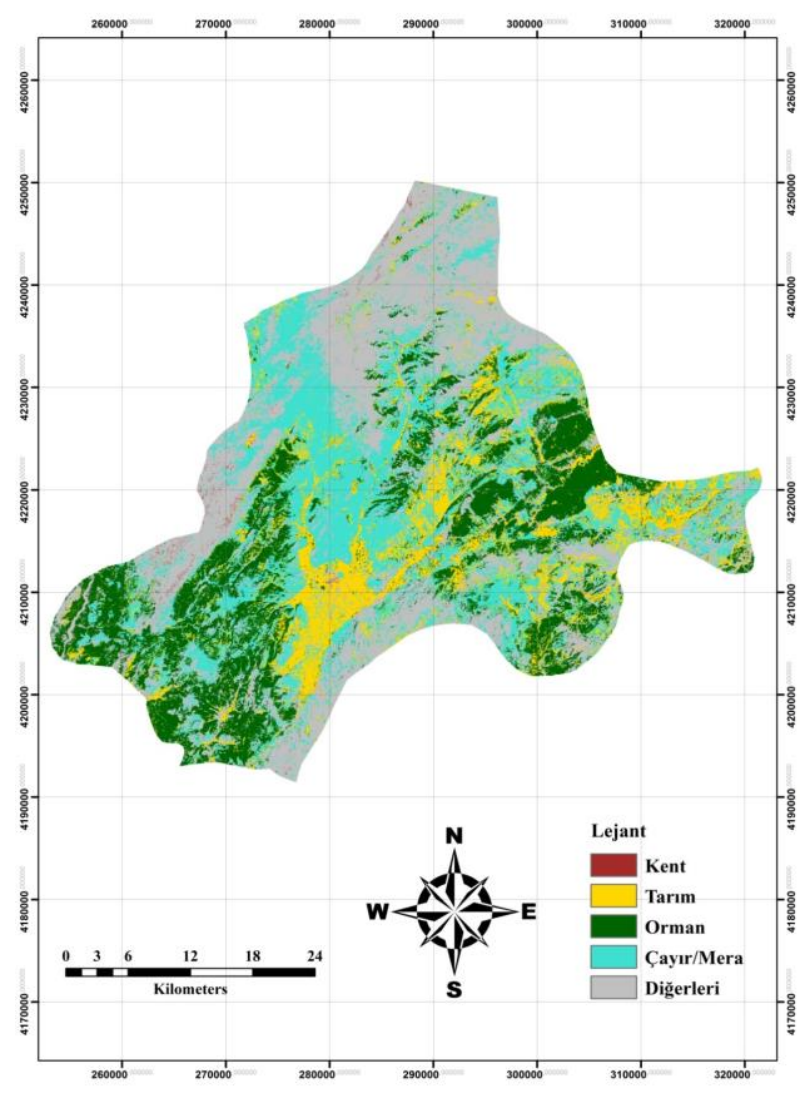

Şekil 2. 1984 yılına ait Arazi Kullanım Sınıfları Haritas1

1984 yılına ait arazi kullanım sınıflarına haritasına göre araştırma alanının \%33,38'i diğerleri, \% 29,31'i çayır/mera, \%22,03'ü orman, \% 14,99'u tarım ve \% 0,29'u kent alanına sahiptir (Tablo 3, Şekil 2).

2011 yılına ait arazi kullanım sınıfları haritasına göre araştırma alanının \% 29,70'i orman, \% 25,77'si diğerleri , \%24,79'u çayır/mera, \% 13,65'i tarım ve \% 6,09'u kent alanına sahip olduğu tespit edilmiştir (Tablo 3, Şekil 4).

1984 ve 2011 yılları arasında geçen 27 yılda meydana gelen arazi kullanım değişimi haritasına göre kent alanlarında $\% \quad 21,53 \quad(10461,2$ ha $)$ orman alanlarında \% 28,47 lik (13836 ha) bir artış meydana gelmiştir. Bununla beraber, tarım alanlarında \% 4,98 (2422,44 ha), çayır/mera alanlarında \% 16,78 (8156,16 ha) ve diğerlerinde \% 28,23 (13718,61 ha) lik bir azalma meydana gelmiştir (Tablo 3 ). 
Tablo 3. 1984 ve 2011 yıllarına ait arazi kullanım sınıflarının alansal (ha) ve oransal (\%) olarak değişim değerleri

\begin{tabular}{|c|c|c|c|c|c|c|}
\hline \multirow{2}{*}{$\begin{array}{c}\text { Arazi } \\
\text { Kullanım } \\
\text { Durumu }\end{array}$} & \multicolumn{2}{|c|}{1984} & \multicolumn{2}{|c|}{2011} & \multicolumn{2}{|c|}{ 1984-2011 Değişen } \\
\hline & Alan (Ha) & $\begin{array}{l}\text { Oran } \\
(\%)\end{array}$ & Alan (Ha) & $\begin{array}{l}\text { Oran } \\
(\%)\end{array}$ & Alan (Ha) & $\begin{array}{l}\text { Oran } \\
(\%)\end{array}$ \\
\hline $\begin{array}{c}\text { Yerleşim } \\
\text { alanı }\end{array}$ & 517,41 & 0,29 & 10978,65 & 6,09 & 10461,2 & 21,53 \\
\hline Tarım & 27026,55 & 14,99 & 24604,11 & 13,65 & $-2422,44$ & $-4,98$ \\
\hline Orman & 39717,72 & 22,03 & 53553,69 & 29,70 & 13836 & 28,47 \\
\hline Çayır & 52851,24 & 29,31 & 44695,08 & 24,79 & $-8156,16$ & - \\
\hline Mera & & & & & & 16,78 \\
\hline Digerleri & 60179,67 & 33,38 & 46461,06 & 25,77 & 13718,61 & 28,23 \\
\hline Toplam & 180292,6 & 100 & 180292,6 & 100 & 0 & .. \\
\hline
\end{tabular}

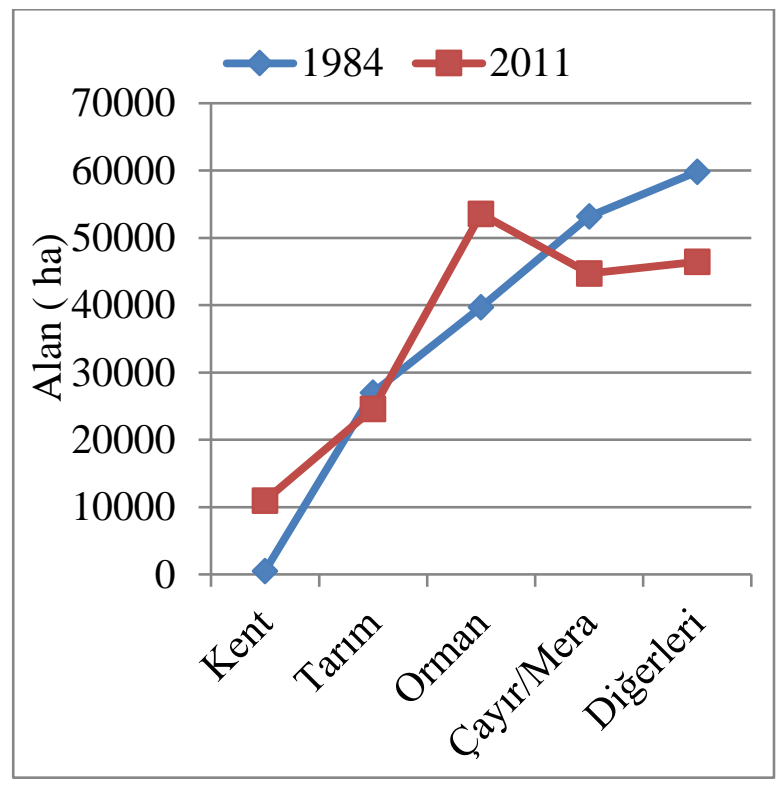

Şekil 3. 1984 ve 2011 yıllarına ait arazi kullanım miktarı (Ha)

1984 ve 2011yıllarına ait uydu görüntüleri için sırasılla genel sinıflandırma doğruluğu $\% 86,80$ ve $\% 84,40$ tespit edilmiş, kappa değerleri de 0,82 ve 0,79 olarak belirlenmiştir. Tahmin doğruluğunun \%80'in üstünde olduğundan sınıflandırmanın doğru ve güvenilir olduğunu göstermektedir (17).

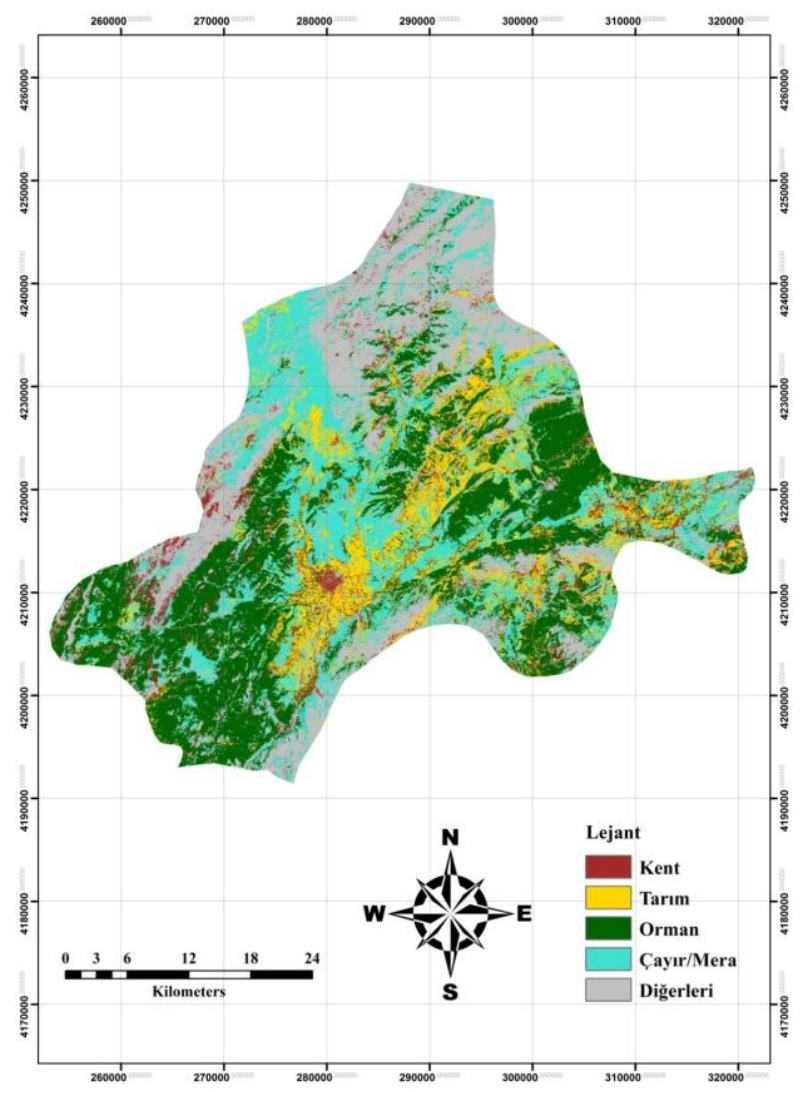

Şekil 4. 2011 yılı arazi kullanım sınıfları haritası

1984 ve 2011 yılları meydana gelen arazi kullanım değişiminde en çok dikkat çeken orman ve kent alanlarının artışıdır (Şekil 3).

Değişim analizi işlemiyle üretilen harita Şekil 5'de gösterilmiştir. Yapılan değişim analizi sonucunda kent alanlarının 3881,16 ha'lık kısmının tarım alanlarından elde edildiği tespit edilmiştir (Tablo 4). Benzer şekilde $\%$ 28,47'lik bir artış gösteren orman alanlarının en fazla çayır/mera alanlarını etkilediği ve 6823,26 ha'lık alanın çayır/mera alanlarından elde edildiği tespit edilmiştir (Tablo 4). 


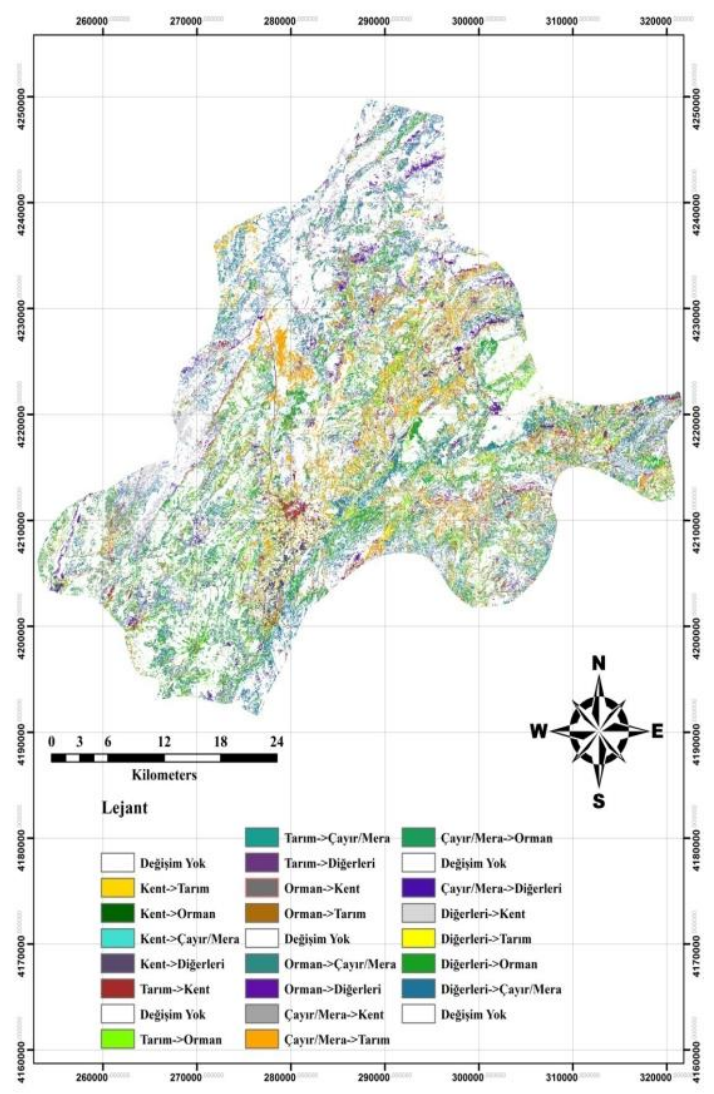

Şekil 5. 1984-2011 yılları arasında meydana gelen arazi kullanım değişimi haritası

Araştırma sonucunda orman alanlarında \% 28,47'lik bir artış tespit edilmiştir. Benzer şekilde, [18] (2011) Kanada' da yaptığı bir çalışmada ormanlık alanlarda \% 16'lık bir artış belirlemiştir. Araştırma alanı için görülen bu artışın dört önemli nedeni bulunmaktadır. Bunlardan birincisi, kırsal alanlardan kentlere göç hareketi nedeniyle orman alanları üzerindeki sosyal baskının azalmasıdır (19, 20 ve 21). Dolayısıyla, ormanlık alanlardaki değişimler özellikle nüfus artışı, kentleşme, yoğun tarım uygulamarı ve sosyo ekonomik durumla yakından ilişkilidir (22). Aşırı nüfus yoğunluğu ve büyüme hızının artması genellikle orman alanları üzerinde olumsuz bir etki oluşturmaktadır $(23,24,25,26,27$ ve 28). Bunun nedeni, halkın temel geçim kaynaklarının geleneksel tarım uygulamaları ve hayvancılık olmasıdır. Bu durum orman alanları üzerinde sosyal baskıyı da artırmaktadır. Ancak, kırsal alanlardan kentsel alanlara göç hareketiyle beraber bu baskı azalmaktadır. Nitekim araştırma alanında 1984 yılında toplam köy nüfusu 42,727 iken 2011 y1lında bu değer 19,090'a düşmüştür. Benzer şekilde, 1984 yılında toplam ilçe nüfusu 15,785 iken bu değer 2011 yılında 34,934'e yükselmiştir. Bu durum ormanlar üzerindeki sosyal baskıyı azaltııştır.

Orman alanlarının artmasında ikinci neden olarak Orman Genel Müdürlüğü tarafından yapılan ağaçlandırma çalışmalarının hayati bir rolü vardır. Türkiye'nin farklı bölgelerinde yapılan çalışmalarda ormanlık alanların artışında ağaçlandırma çalışmalarının etkili olduğunu belirtmişlerdir (19, 20 ve 21). OGM 1946 dan 2010 yılına kadar yaklaşık 2 milyon hektar ağaçlandırma yapmıştır (29). Benzer şekilde, dünya çapında orman plantasyonları 1990 dan 2010 yılına kadar 178,3 milyon ha dan 264 milyon hektara ulaşmış ve gelecek 10 yılda artışın \% 1'in üzerinde olacağ 1 tahmin edilmektedir (30).

Üçüncü nedeni, terkedilen alanların yakında bulunan ormanlardan gelen tohumlar sayesinde alana doğal gençliğin gelmesidir. Dördüncüsü neden olarak ise, mevcut orman ekosistemlerinin korunması ve gelişimi için çalışan Orman Genel Müdürlüğü’nün son zamanlarda doğru ve başarılı silvikültürel uygulamaları gösterilebilir (20).

Tarım alanları incelendiğinde, 1984 ve 2011 yılları arasında yaklaşık \%5'lik bir azalma görülmektedir. Nitekim, [31] (2011) Kahramanmaraş kent merkezinde yaptıkları bir çalışmada tarım alanlarının yaklaşık 40,000 ha azaldığını belirtmiştir. Araştırma alanında olduğu gibi, hızla artan insan nüfusuyla birlikte yerleşim, sosyal yaşam, sanayileşme vb. ihtiyaçlar için arazi istekleri her geçen gün artmaktadır. Bu durum sonucunda tarım, mera vb. alanlar tahrip edilmektedir. Nitekim, [32] 2011yılında Samsun'un merkez ilçesinde yaptığı çalışmada tarım alanlarının 1984 yılında toplam alanın \% 71,31'ini kapladığını, 2005 yılında ise tarım alanlarının toplam alanın \% 29,69’unu oluşturduğunu belirlemiştir.

Tablo 4. 1984 ve 2011yılı arazi kullanımının alan bazında değişimi

\begin{tabular}{|c|c|c|c|c|c|}
\hline & \multicolumn{5}{|c|}{2011 Yılı Arazi Kullanımı (Ha) } \\
\hline 1984 Arazi Kullanımı & Kent & Tarım & Orman & Çayır/Mera & Diğerleri \\
\hline Kent & - & 8,19 & 5,31 & 16,2 & 332,19 \\
\hline Tarım & 3881,16 & - & 5702,04 & 3891,42 & 1743,66 \\
\hline Orman & 964,17 & 1833,75 & - & 1101,51 & 859,5 \\
\hline Çayır/Mera & 2606,31 & 8776,17 & 6823,26 & - & 5995,62 \\
\hline Diğerleri & 3373,02 & 2197,44 & 6075,36 & 10774,8 & - \\
\hline
\end{tabular}


Çayır/mera alanlarında 1984-2011 yılları arasındaki dönemde yaklaşık \% 16 oranında bir azalama görülmüş bu durum öncelikle çok eskiden beri kullanılmakta olan mera, yaylak, kışlak vb. yerlerin artık kullanılmamasıyla diğer kullanım alanlarına dönüşmesinden kaynaklanmaktadır. Yapılan farklı çalışmalarda ise $(33,1,34$ ve 35) mera alanlarının yıllar itibarı ile azaldığ alanlarının yol, yerleşim ve sanayi alanı olarak kullanılmaya başlanması, tarım alanlarının mera alanları üzerine doğru genişlemesi gibi nedenler olduğu belirtilmektedir.

Bununla birlikte, 1999 yılında çıkarılan 4342 sayılı mera kanunun 6. maddesine göre "mera, yaylak ve kışlakların tespit, tahdit ve tahsis" işlemleri için "mera komisyonları"görevlendirilmiştir. Ancak, Türkiye'de doğal mera alanlarının özelliklerini çok iyi bilen tecrübeli meracıların sayısı oldukça azdır. $\mathrm{Bu}$ nedenle, oluşturulan mera komisyonları doğal mera alanlarının tespiti işlemlerinde yetersiz kalmaktadır. Bu durum, mera olarak kullanılması gereken pek çok alanın mera alanları dışına çıkmasına neden olmaktadır. Oldukça geniş mera sahalarına sahip Türkiye'nin mera alanlarını gerektiği gibi yönetecek bir teşkilatının kurulması zorunluluk arz etmektedir. Araştırma alanındaki arazi kullanımında ve demografik yapıdaki değişimlerin zamana bağlı olarak takip edilmesi, su verimi ve kalitesi başta olmak üzere pek çok doğal unsurun korunması ve geliştirilmesi bakımından önem taşımaktadır.

\section{KAYNAKLAR}

[1]. Gülersoy, A.E. 2014.Seferihisar'da arazi kullanımının zamansal değişimi ve ideal arazi kullanımı için öneriler, SDÜ Fen Edebiyat Fakültesi, Sosyal Bilimler Dergisi, Isparta.

[2]. Karakoç, A. 2011. Göksu Deltası'nda (SilifkeMersin) meydana gelen değişimlerin uzaktan algılama teknikleri ile incelenmesi. Yayımlanmış Yüksek Lisans Tezi, Kahramanmaraş Sütçü İmam Üniversitesi Sosyal Bilimler Enstitüsü.

[3]. Çepel, N., 1996. Çevre koruma ve ekoloji Sözlüğü, TEMA Vakfi Yayınları No: 6, İstanbul.

[4]. Sarı, M., 2006. Türkiye'deki arazi varlığı ve bu arazilerin erozyona olan duyarlılığı, http://www.aof.edu.tr.

[5]. Knapp, S., 2010. Plant Biodiversity in urbanized areas, 1st edition, ISBN 978- 3-8348-0923-0.

[6]. Cincotta, R and Gorenflo, L. J.(Ed.) 2011. Human Population: Its Influences on Biological Diversity, Ecological Studies, Vol. 214, pp. ISBN 978-3-64216706-5.

[7]. Duran, C., Günek, H., 2007 Hazar gölü havzası arazi kullanımındaki değişikliklerin belirlenmesi
(1956- 2004), Furat Üniversitesi Sosyal Bilimler Dergisi, Cilt: 17, Sayı: 2 Sayfa:31-52, Elazığ.

[8]. Tezcan, S., 2008. Türkiye'de göç boyutu, nedenleri ve göçün sağlıkla ilişkisi, Sağlıklı Kentler Birliği Eğitim Programı.

[9]. Tuik, 2009. Adrese dayalı nüfus kayıt sistemi, 2008 nüfus sayımı sonuçları, Türkiye istatistik kurumu.

[10]. Manonmani, R., Suganya, G., 2010. İnternational Journal Of Geomatics and Geosciens volume 1, No 1, ISSN 09764380 p. 60-65.

[11]. Karabulut, M., Küçükönder, M., Gürbüz, M., Sandal, E.K., 2006. "Kahramanmaraş şehri ve Çevresinin Zamansal Değişiminin Uzaktan Algılama ve CBS Kullanılarak İncelenmesi”, 4. Coğrafi Bilgi Sistemleri Bilişim Günleri Bildiriler Kitab1, İstanbul.

[12]. Iderman, E., 2006. Salamis antik kenti ve çevresinin uzaktan algılama ve coğrafi bilgi sistemleri kullanılarak tarihsel ve güncel arazi kullanımları yönünden incelenmesi, Yüksek Lisans Tezi Çukurova Üniversitesi Fen Bilimleri Enstitüsü, Adana.

[13]. Jensen, J. R. 1996. Introductory digital 1mage processing: a remote sensing perspective (2nd Edition). Prentice Hall, Upper Saddle River, New Jersey, USA.

[14]. Karabulut, M., 2006. "NOAA AVHRR verilerini kullanarak Türkiye'de bitki örtüsünün izlenmesi ve incelenmesi”, Coğrafi Bilimler Dergisi, 4 (1), ss. 29-42.

[15]. Tarhan, Ç. 2004. Planlamada uzaktan algılama ve coğrafi bilgi sistemi disiplinleri entegrasyonu: Urla ve Balçova örnekleri, ĠYTE şehir ve Bölge Planlama Bölümü Planlama 2004/3 s.106-112.

[16]. Erdas, 2001. Erdas tour guide, erdas 1nc. Atlanta, Georgia.

[17]. Güney, Y., Ölgen, M.K., 2009. Landsat uydu görüntüleri yardımıyla Bornova'da arazi kullanımı değişiminin belirlenmesi, 3.DEÜ CBS Sempozyumu.

[18]. van Lier, O.R., Luther, J.E., Leckie, D.G., Bowers, W.W., 2011. Development of large-area land cover and forest change indicators using multisensor Landsat imagery: application to the Humber River Basin, Canada. Int J App Earth Obs 13:819829.

[19]. Başkent, E.Z., Kadığulları, A., 2007. Spatial and temporal dynamics of land use pattern in Turkey: a case study in İnegöl. Landsc Urban Plan 81:316327 Cincotta, R., Gorenflo, L. J.(Ed.) 2011. Human Population: Its Influences on Biological 
Diversity, Ecological Studies, Vol. 214, pp. ISBN 978-3-642-16706-5.4.

[20]. Sivrikaya, F., Çakır, G., Kadıŏulları, A., Keleş, S., Başkent, E.Z., Terzioğlu, S., 2007. Evaluating land use/land cover changes and fragmentation in the Camili forest planning unit of northeastern Turkey from 1972 to 2005. Land Degrad Dev 18:383-396.

[21]. Çakır, G., Sivrikaya, F., Keleş, S. 2008. Forest cover change and fragmentation using Landsat data in Macka state forest enterprise in Turkey. Environ Monit Assess 137:51-66.

[22]. Verburg, P. H., Veldkamp, A., Bouma, J. 1999. Land-use change under conditions of high population pressure: The case of Java. Global Environmental Change, 9, 303-312.

[23]. Siebert, S.F. 1987. Land use intensification in the tropical uplands: effects on vegetation, soil fertility and erosion. Forest Ecology And Management $21: 37-56$.

[24]. Collier, G.A., Mountjoy, D.C., Nigh, R.B. 1994. Peasant agriculture and global change, BioScience 44: 398-407.

[25]. Uitto, J.I. 1995. Population, land management and environmental change: the genesis of PLEC within the United Nations University Programme. Global Environment 5: 267-270.

[26]. Frohn, R.C., McGwire, K.C., Dale, V.H., Estes, J. E. 1996. Using satellite remote sensing analysis to evaluatea socio-economic and ecological model of deforestation in Rondonia, Brazil. International Journal Remote Sensing 17: 3233-3255.

[27]. Cuffaro, N. 1997. Population growth and agriculture in poor countries:a review of theoretical issues and empiricalevidence. World Development 25: 1151-1163.

[28]. Pender, J.L. 1998. Population growth, agricultural intensification, induced innovation and natural resource sustainability: an application of neoclassical growth theory. Agricultural Economics 19: 99-112.

[29]. OGM, 2013. Orman genel müdürlüğü performans program1, Ankara.

[30].FAO, 2010. Global forest resource assessment 2010 main report. FAO, Rome.

[31]. Oğuz, H., Zengin, M.,2011. Peyzaj patern metrikleri ve landsat $5 \mathrm{tm}$ uydu görüntüleri kullanılarak arazi örtüsü/arazi kullanımı değişimi analizi (1984 - 2010): Kahramanmaraş Örneği I. Ulusal Akdeniz Orman ve Çevre Sempozyumu, 26-28 Ekim 2011, Kahramanmaraş.
[32]. Dengiz, O., Turan, İ.D., 2014. Uzaktan algilama ve coğrafi bilgi sistem teknikleri kullanılarak arazi örtüsü / arazi kullanımı zamansal değişimin belirlenmesi: Samsun merkez ilçesi örneği (19842011), Türkiye Tarımsal Araştırmalar Dergisi, 1(1): sayfa: 78-90.

[33]. Gülersoy, A. E., 2013. Çorum merkez ilçede arazi kullanımının zamansal değişimi (1987-2011) ve çevresel etkileri, Coğrafi Bilimler Dergisi, 169194, İzmir.

[34]. Somuncu, M., Akpınar, N., Kurum, E., Çabuk, K.N., Özelçi, E. T., 2010. gümüşhane ili yaylalarındaki arazi kullanımı işlev değişiminin değerlendirilmesi: Kazıkbeli ve Alistire yayları örneği, Ankara Üniversitesi, Çevre Bilimleri Dergisi.

[35]. Özşahin, E., Atasoy, A., 2014. Aşağı Asi nehri havzası'nda ( Hatay ) arazi kullanımı ve arazi örtüsü değişiminin ( 1990-2011 ) Erozyon Üzerindeki Etkisi, Uluslar Arası Sosyal Araştırmalar Dergisi, Cilt:7, Sayı:3. 